\title{
Continuity of Kimberley-type pyroclastic kimberlite phases within Renard 2 over 1,000 m depth - Insights to the geological and emplacement model, Superior Craton, Canada
}

\author{
Zhuk, V. ${ }^{1}$, Lépine, I. $^{1}$, and Laroulandie, C. $^{1}$ \\ ${ }^{1}$ Stornoway Diamond Corporation, North Vancouver, Canada \\ vzhuk@stornowaydiamonds.com, ilepine@stornowaydiamonds.com, claroulandie@stornowaydiamonds.com
}

\section{Introduction}

The Renard 2 kimberlite pipe is the largest body within a cluster of nine diamondiferous pipes emplaced approximately $640 \mathrm{Ma}$ into Archean granitoid and gneissic rocks of the eastern portion of the Superior Craton, Canada (Fitzgerald et al, 2009). Located in the Otish Region of northern Québec, Renard 2, a mid-sized pipe with a surface expression of approximately 2.3 hectares, currently forms the bulk of feed to Stornoway Diamond Corporation's newly commissioned Renard Mine. Kimberlite pipes within the Renard cluster are all characterized by similar Kimberley-type pyroclastic kimberlite (KPK; formerly termed TK or tuffisitic kimberlites). Renard 2 is a diatreme- to root-zone kimberlite consisting of two main KPK pipe-infills (Kimb2a and Kimb2b) characterised by distinct diamond grades and determined as emplacement products from distinct and separate batches of magma. In addition, a third phase, Kimb2c, classified as hypabyssal kimberlite, occurs in the form of irregular intrusions and late stage cross cutting dykes. This phase is found within and along contacts of Kimb2a and $\mathrm{Kimb} 2 \mathrm{~b}$, as well as along wall rock contacts, and contributes an average of $17 \%$ by volume to the modelled kimberlite pipe. A marginal country rock breccia, CRB, envelopes the KPK units, and smooths the external pipe shape.

Culminating with a deep directional drilling campaign in 2014, detailed petrological, dilution, geochemical and diamond grade data derived from $>45 \mathrm{~km}$ of diamond drilling confirmed vertical continuity of the two KPK phases on Renard 2, through more than 1,000 m, and provided for an updated robust geological model to a depth of 865 meters (Figure 1) (Lépine and Farrow, 2017) as well as new perspective into the emplacement.

\section{Geology and Petrology}

The Renard 2 main pipe-infills, Kimb2a and Kimb2b, exhibit contrasting primary features: olivine abundances and populations, country rock xenolith abundances and populations as well as groundmass mineralogy. Kimb2a is volumetrically the most significant phase infilling the pipe, accounting for $70 \%$ of total kimberlite by volume. It consists of olivine, pyroclasts and country rock xenoliths that are poorly sorted, typically loosely packed and less commonly clast supported, and set within a highly altered interclast matrix. Olivine macrocrysts comprise 5-15 modal \% of the rock and are typically medium-grained to rarely coarse-grained. Primary groundmass minerals within pyroclasts include phlogopite, spinel and perovskite. This unit commonly contains $40-65$, and up to 95 modal \% fresh to moderately altered granitoid and gneissic country rock xenoliths. These are set within a non-crystalline matrix that comprises clays, serpentine and microlitic clinopyroxene. Kimb2a can be classified mineralogically as a phlogopite kimberlite.

Kimb $2 b$ accounts for $30 \%$ of total kimberlite by volume and reveals very similar mostly coherent, to limited pyroclastic, textures throughout the entire geological model, with olivine, country rock xenoliths and rare pyroclasts that are unsorted and set within a crystalline to semi-crystalline groundmass. Olivine macrocrysts comprise 10-25 modal \% of the rock and are medium- to coarsegrained with common very coarse-grained crystals. The Kimb2b groundmass consists of primary minerals of phlogopite, spinel, perovskite, carbonate and rare monticellite, and late stage minerals of serpentine, clays and microcrystic clinopyroxene. This unit commonly contains 20-50 modal \% 
moderately to strongly altered gneissic and less abundant granitoid country rock xenoliths. Kimb2b can be classified mineralogically as a monticellite-phlogopite kimberlite.

Hypabyssal kimberlite Kimb2c occurs in Renard 2 in the form of late-stage HK dykes and irregular intrusions. Kimb2c phases present within Kimb2a and Kimb2b form up to $14 \%$ and $25 \%$ of their volumes, correspondingly. The various HK intrusions include a spectrum of primary groundmass mineral assemblages, ranging from monticellite dominated to phlogopite dominated, each additionally consisting of common carbonate, spinel and perovskite.

The kimberlite in Renard 2 is surrounded by extensive marginal country rock breccia. This CRB has a maximum width of approximately $100 \mathrm{~m}$ near surface and extends the full depth of the body on the north side of the pipe. Importantly, the Kimb2c hypabyssal dykes (although not modelled in 3D) are also present within the CRB unit, and form up to $10 \%$ of its volume contributing to diamond grade of the CRB.

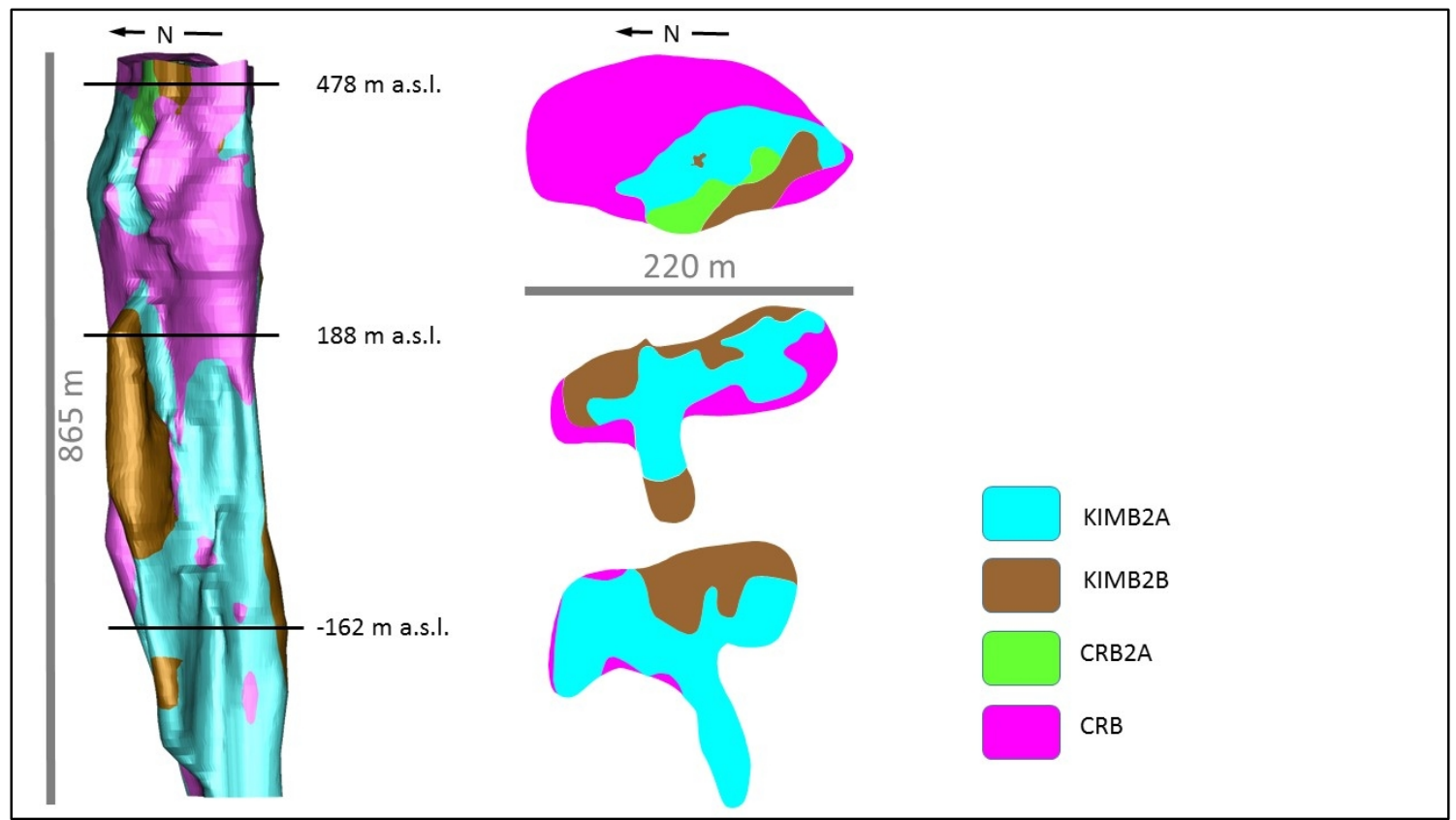

Figure 1: Renard 2 kimberlite 3D geological model (left) with the Kimb2a and Kimb2b major kimberlite infills and the enveloping CRB, and plan views (right) at vertical levels of $478 \mathrm{~m}$ a.s.l., $188 \mathrm{~m}$ a.s.l., and $-162 \mathrm{~m}$ a.s.l. (above sea level).

Detailed petrological, petrographic, and internal dilution data derived from $>45 \mathrm{~km}$ of diamond drilling (161 holes) confirmed vertical continuity of both KPK phases, Kimb2a and Kimb2b, through more than $1,000 \mathrm{~m}$.

\section{Geochemistry}

Geochemical signatures for Kimb2a and Kimb2b were sampled through a series of $50 \mathrm{~m}$ horizontal slices from the surface to depth of 865 meters below surface.

Whole rock analyses, including $\mathrm{C}, \mathrm{S}$ and LOI, and Ni identify distinctive geochemical differences between the Kimb2a and Kimb2b phases but demonstrate continuity by phase with depth. There is also a consistent pattern of increasing $\mathrm{SiO}_{2}, \mathrm{Al}_{2} \mathrm{O}_{3}, \mathrm{Na}_{2} \mathrm{O}$ and $\mathrm{K}_{2} \mathrm{O}$ with increasing levels of country rock dilution: lower in Kimb2b and higher in Kimb2a, but the average dilution itself remains consistent with increasing depth. 
The LREE elements are elevated in the less diluted Kimb2b (and in Kimb2c), which reflects the more primitive rock composition associated with kimberlite. HREE values tend to overlap between the phases with more elevated values appearing in the heaviest REE (Er, $\mathrm{Yb}$ and $\mathrm{Lu}$ ) in Kimb2a.

The incompatible elements $\mathrm{Cs}, \mathrm{Rb}, \mathrm{K}, \mathrm{Hf}, \mathrm{Zr}$ and $\mathrm{Y}$ are generally elevated in Kimb2b or Kimb2a, respectively, in comparison to Kimb2c. Incompatible elements $\mathrm{Ta}, \mathrm{Nb}$, and $\mathrm{Ti}$ are increasingly depleted in Kimb2b and Kimb2a, respectively, compared to Kimb2c but again remain consistent with depth.

First series transition elements $\mathrm{Ti}, \mathrm{Cr}, \mathrm{Co}$ and $\mathrm{Ni}$ are depleted in the more dilute Kimb2a and Kimb2b samples compared to Kimb2c. Manganese appears depleted in Kimb2a, but not Kimb2b, when compared to Kimb2c, and all are consistent with depth.

The geochemical signatures for Kimb2a and Kimb2b from each $50 \mathrm{~m}$ horizontal slice are proved consistent individually and on a level by level basis from the surface to depth of 865 meters below surface, corresponding to the current extent of the 3D geological model.

\section{Diamond Content}

To test for continuity of diamond content within each phase of kimberlite, and with depth in the Renard 2 body, sampling for microdiamonds and macrodiamonds was undertaken on $50 \mathrm{~m}$ levels from surface to the base of the modelled body at $1,000 \mathrm{~m}$ below surface $(-352 \mathrm{~m}$ a. s. 1.). Within each $50 \mathrm{~m}$ level, approximately $200 \mathrm{~kg}$ from each of Kimb2a and Kimb2b was collected from drill core and treated for microdiamond recovery. A total of 4,141 kg of Kimb2a and 3,844 $\mathrm{kg}$ of Kimb2b were analyzed by standard caustic dissolution. Totals of 1,496 diamonds and 3,117 diamonds larger than $0.106 \mathrm{~mm}$ square mesh were recovered from Kimb2a and Kimb2b respectively. When combined with overall diluted macrodiamond sampling of Kimb2a and Kimb2b, the undiluted diamond size frequency distribution plots in each of the $50 \mathrm{~m}$ depth slices demonstrate good grade continuity with increasing depth. The modelled undiluted adjusted grades were $83 \mathrm{cpht}$ and $181 \mathrm{cpht}$ for Kimb2a and Kimb2b, correspondingly (Farrow and Hopkins, 2015).

\section{Discussion and Conclusion}

Petrology, internal country rock dilution, geochemistry, and diamond content studies of the two main KPK pipe-infills at Renard 2 (Kimb2a and Kimb2b) confirm vertical continuity of the Kimberley-type pyroclastic kimberlite phases through more than $1,000 \mathrm{~m}$.

The findings of this work provide new insight into the geological and emplacement model, with a diatreme-zone vertically continuous through over $1 \mathrm{~km}$; a rare and notable feature for Canadian kimberlites.

\section{References}

Fitzgerald CE, Hetman CM, Lépine I, Skelton DS, McCandless TE (2009) The internal geology and emplacement history of the Renard 2 kimberlite, Superior Province, Quebec, Canada. Lithos 112S 513-528

Lépine I and Farrow D J (2017) 3D geological modelling of the Renard 2 Pipe, Québec, Canada: from exploration to extraction. 11th International Kimberlite Conference Extended Abstract No. 11IKC4545, 2017, Gaborone, Botswana.

Farrow D and Hopkins R (2015) Mineral Resource Update for the Renard Diamond Project, Quebec, Canada. National Instrument (NI) 43-101 Technical Report: 139p. 